\title{
Corrigendum
}

\section{Self-rated attention to detail predicts threat detection performance in security $\mathrm{X}$-ray images}

\author{
Elena Rusconia, b,*, Eamon McCrory ${ }^{\mathrm{c}}$ and Essi Viding ${ }^{\mathrm{c}, \mathrm{d}}$ \\ ${ }^{a}$ Department of Security and Crime Science, University College London, 35 Tavistock Square, \\ London WC1H 9EZ, UK. \\ E-mail: elena.rusconi@gmail.com \\ ${ }^{b}$ Department of Neurosciences, Section of Physiology, University of Parma, Via Volturno 39/E, \\ I-43100 Parma, Italy. \\ ${ }^{c}$ Division of Psychology and Language Sciences, University College London, 26 Bedford Way, \\ London WC1H 0AP, UK. \\ ${ }^{\mathrm{d} I n s t i t u t e}$ of Cognitive Neuroscience, University College London, 17 Queen Square, London WC1N 3AR, UK. \\ *Corresponding author.
}

Security Journal (2012) 25, 372. doi:10.1057/sj.2011.29

Correction to Security Journal (2011) 10.1057/sj.2011.27

The sample size for the high-scoring group was 14 , and the sample size of the low-scoring group was 15 (as correctly shown in Figure 3b), and not the other way around (as stated in the body text). 